\title{
El Centro Experimental de Pirwaccocha - Churcampa*
}

\author{
http://dx.doi.org/10.21503/CienciayDesarrollo.2014.v17i2.08
}

Este Centro se ubica en el distrito de Churcampa (Provincia Churcampa) Huancavelica, a una altitud de 2500 - 2700 metros y se enmarca dentro del proyecto de manejo de pisos ecológicos que la Universidad Alas Peruanas ejecuta desde el año 2000 en esta región, ubicada entre los dos mil y cuatro mil doscientos metros de altura, comprendiendo ecozonas yungas y de punas por sus características geográficas.

La experiencia ha demostrado un clima propicio para la siembra de fresas (Fragaria vesca) y en especial para la palta (Persea americana L.) cuyas variedades Hass y Fuerte han dado óptimos resultados.

Como un avance en el informe de resultados: la siembra ocupa un área de cuatro hectáreas regadas por goteo, obteniéndose una producción de 100 kilos en la primera cosecha/hectárea y 150 kilos en la segunda con un promedio de 250 - 300 frutos por planta.

Esta experiencia es trasmitida a las comunidades vecinas para la promoción y desarrollo de esta economía frutícola, como alternativa para el mejoramiento de la calidad de vida de los pobladores.

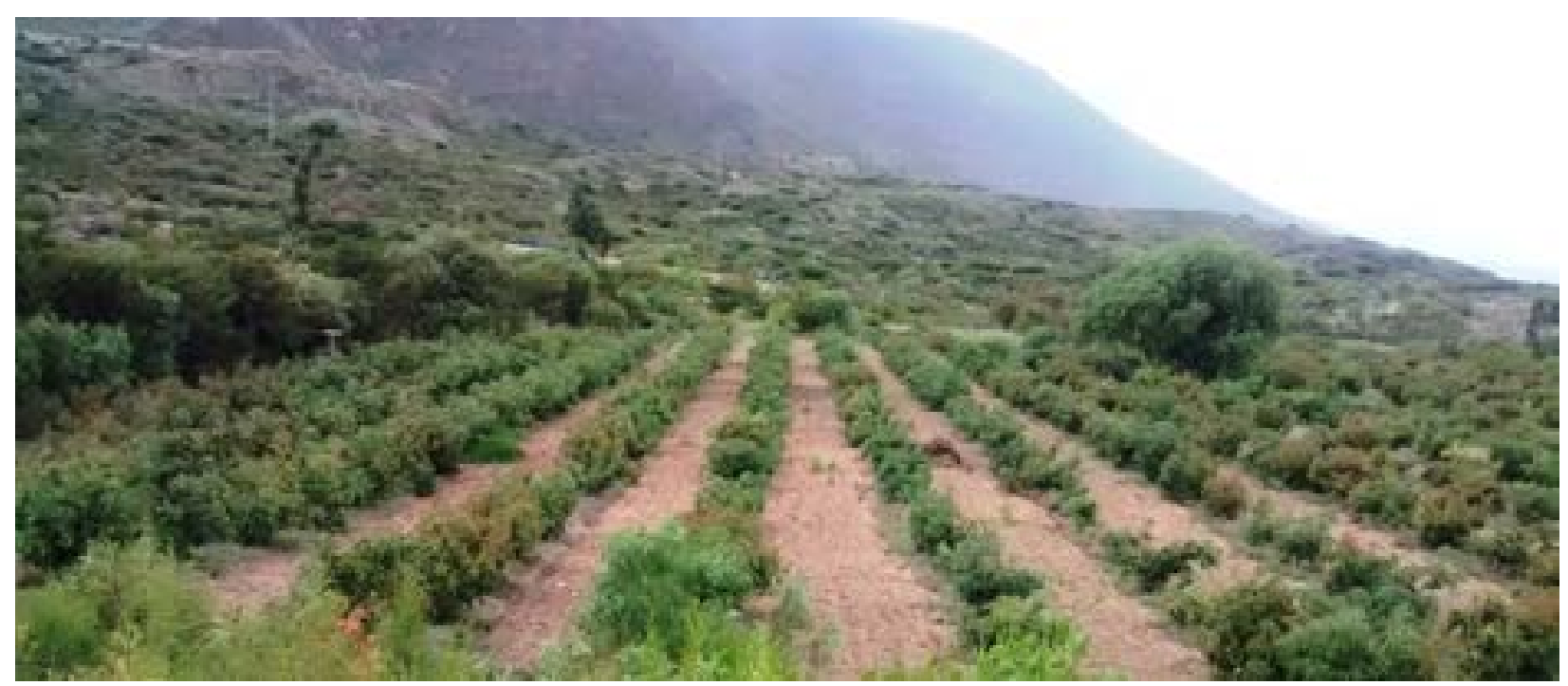

Figura 1: Centro Pirwaccocha

1 Interesados comunicarse a la dirección de esta revista o al director responsable del Centro Pirwaccocha Dr. Mauro Estrada Gamboa. 


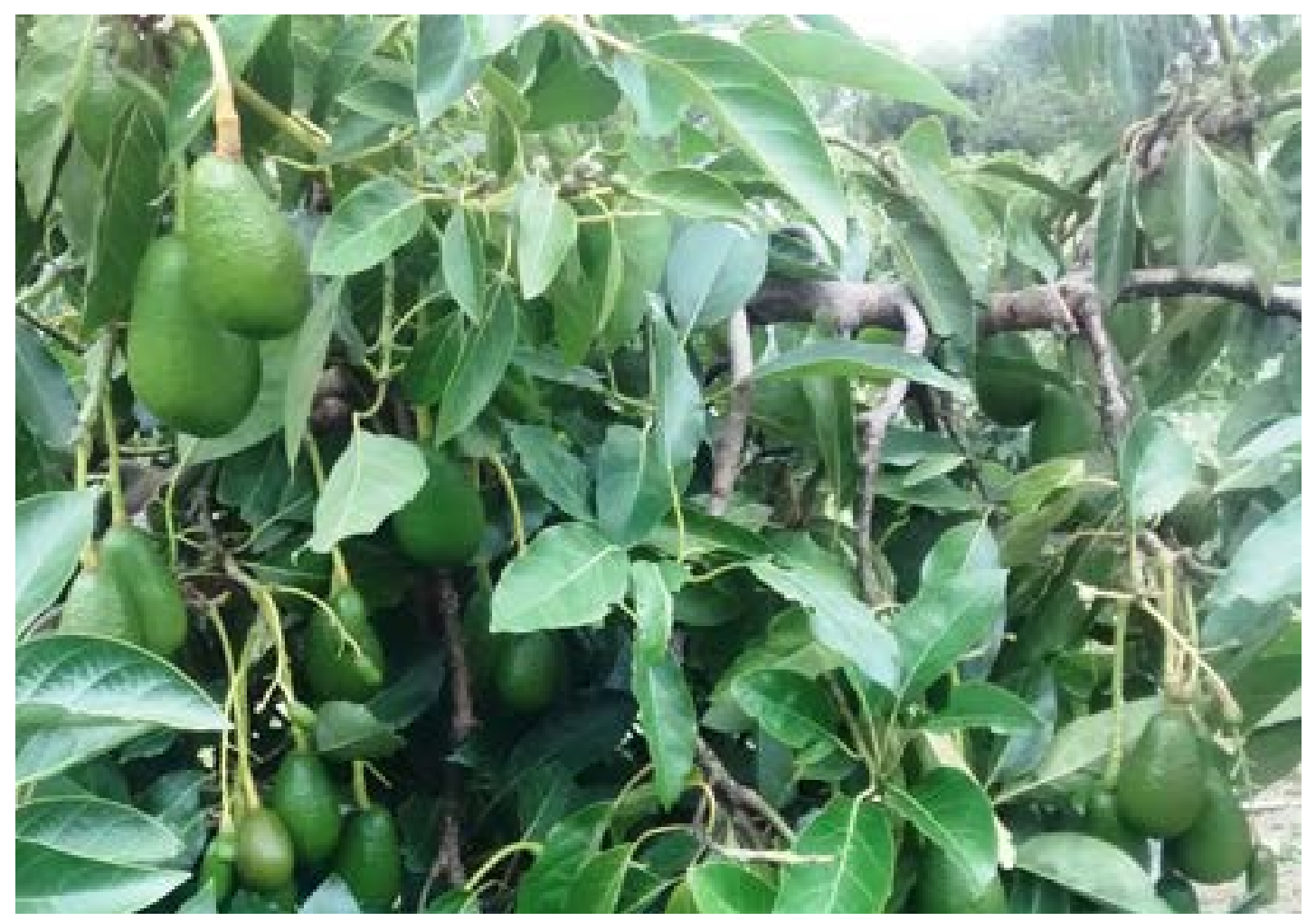

Figura 2

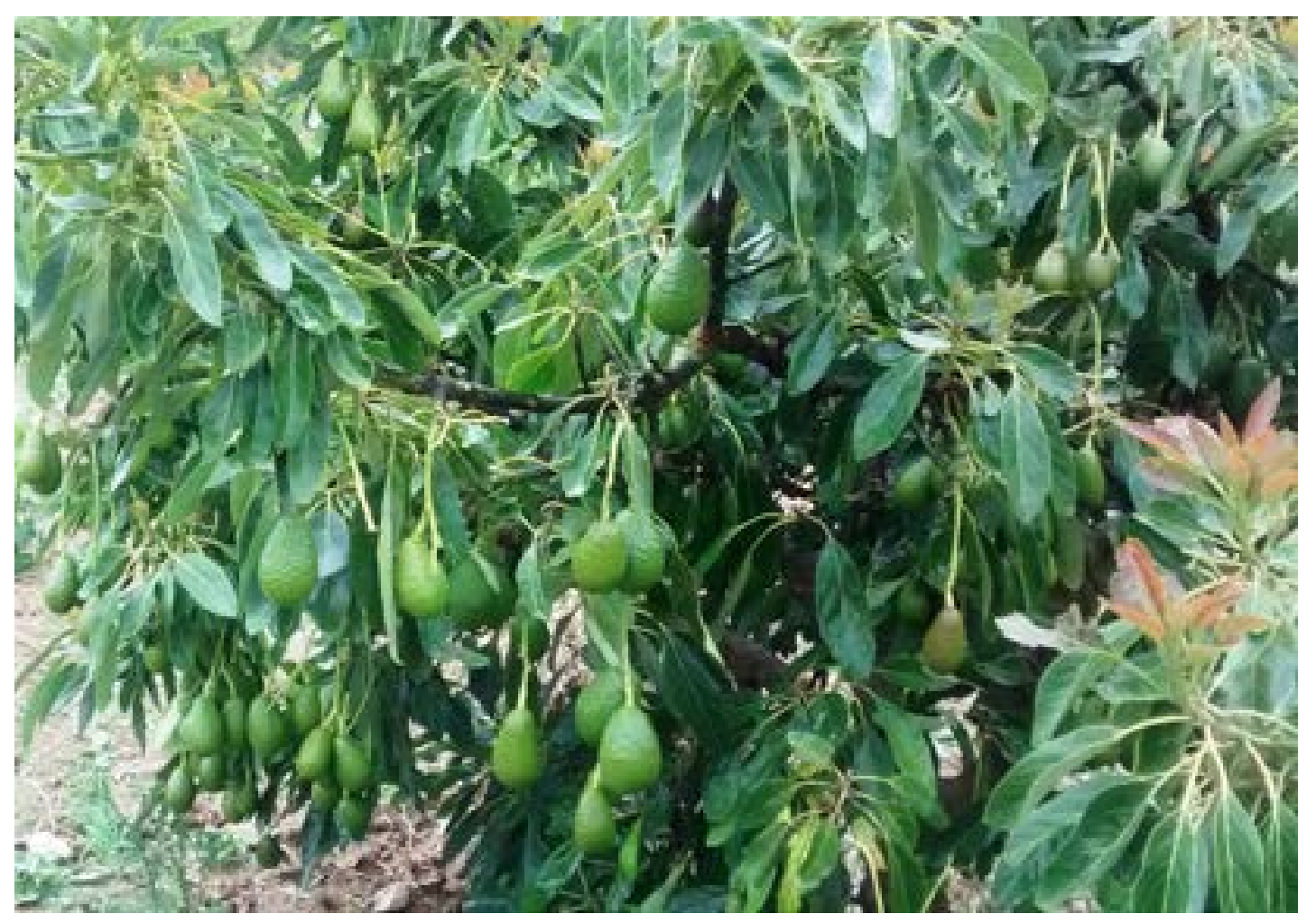

Figura 3 


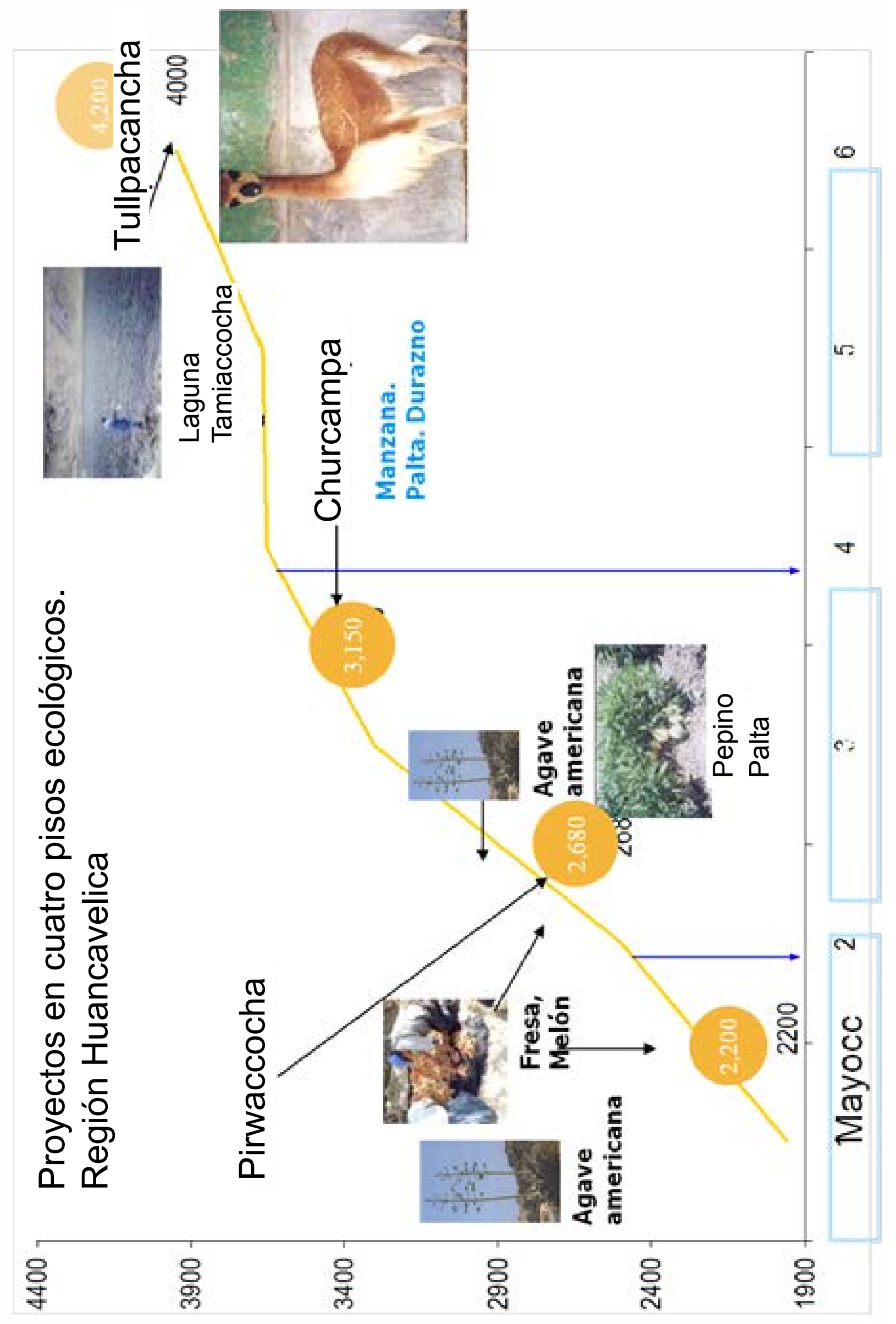

